\title{
Annular epidermolytic ichthyosis
}

INSERM

\section{Source}

INSERM. (1999). Orphanet: an online rare disease and orphan drug data base. Annular epidermolytic ichthyosis. ORPHA:281139

Annular epidermolytic ichthyosis (AEI) is a rare clinical variant of epidermolytic ichthyosis (El; see this term) characterized by the presence of a blistering phenotype at birth and the development from early infancy of annular polycyclic erythematous scales on the trunk and extremities. 